\title{
Geomechanical safety aspects in hard rocks mining based on room-and-pillar and longwall mining systems
}

\author{
Witold Pytel \\ KGHM CUPRUM R\&D, Wroclaw, Poland \\ Bogumila Palac-Walko \\ Faculty of Geoengineering, Mining and Geology, Wroclaw University of Science and Technology, Poland \\ Piotr Mertuszka \\ KGHM CUPRUM R\&D, Wrocław, Poland
}

\begin{abstract}
SUMMARY: The article discusses geomechanical aspects and numerical simulations associated with the mining methods dedicated for flat or flatly dipping orebody, i.e. room-and-pillar and longwall mining systems with regard to development of hypothetical mining panel. It was assumed that the overburden strata consists of several homogeneous rock plates reflecting the typical lithology in the Lower Silesia area. The results of the computer 3D simulations permitted elastic-plastic rock mass stability analysing, identifying the areas being more susceptible to damage. Each model has been analysed from the point of view of different methods of roof control. The geomechanical risk assessment procedure utilized so called safety margins which were defined as a distance between the point characterized by the actual local strain/stress conditions and the instability (limit) surface(s) which location in the 3D stress/strain space could be determined using different strength theories. The obtained results have proved that in the considered geological conditions, room-and-pillar approach has a significant advantage from point of view geomechanical safety, over the mechanized longwall excavation system.
\end{abstract}

Keywords: numerical modelling, geomechanical hazard, room-and-pillar and longwall mining systems

\section{INTRODUCTION}

Currently, exploitation of hard rock deposits in deep underground mines is performed primarily by the use of blasting technology. However presently, new technologies based on a mechanized type of rock mass excavation technologies are also under development (Spisak and Zelko, 2015). An important factor affecting the mining method selection is the hardness of the rock and the adapted mining system. Apart from the mechanical excavating system, different varieties of room-and-pillar, sublevel, shrinkage and other mining methods are used. The implementation of mechanical excavation systems in world's hard rock mines haven't reached a level of success so far. Several attempts have indicated that due to the presence of hard rocks in the deposit, proposed road headers and continuous miners haven't proved themselves to be so effective as they were expected. 
Therefore the main goal of the presented analyses is to evaluate geomechanical aspects associated with two mining methods, i.e. longwall mining and room-and-pillar mining system with regard to excavating of hypothetical mining panel. Both methods are well suited to extracting the relatively flat deposits. Room-and-pillar mining system is quite effective, relatively safe, and fits well under tight geomechanical conditions, which are typical for flat deposits. However, this is a longwall mining which is still more efficient from point of view of productivity, compared with room-and-pillar mining (Spisak and Zelko, 2010). This is because the longwall mining is in principle a continuous operation which require smaller crew and allow for a high rate of production.

Today, 3D computer simulations of extensive mining operations performed underground permit elastic-plastic rock mass stability analysing aimed for identifying the areas being more susceptible to damage, presently and in a far future. The geomechanical risk assessment procedure utilized so called safety margins which were defined as a distance between the point characterized by the actual local strain/stress conditions and the instability (limit) surface(s) which location in the 3D stress/strain space could be determined using the well-known strength theories (Palac-Walko and Pytel, 2015).

\section{GENERAL DESCRIPTION OF CONSIDERED MINING SYSTEMS}

Room-and-pillar mining system (Figure 1) is a dominant technology utilized in underground metal and chemical raw material mines (Hustrulid and Bullock, 2001). Mine workings' rational design requires the ability for pillar bearing capacity prediction as well as its load-deformation characteristics, since these factors permit control of pillar loads and surface and roof deflection. On the other hand, the load acting onto a given pillar depends on some effects created by surrounding geological and mining environment. Yield pillars offer a number of advantages that may result in improved stability in gate and tail entries, reduced seismic risk, and reduced subsidence curvature and slope values. This was proven in the deep coal mines in USA (e.g. Mark, 1990) as well as in Polish mines where so called 'roof deflection' technology, based on yield pillar mechanics, has been successfully implemented (Butra et al., 2001). However, since the empirical type of the technique has been used for yield pillar size selection (KGHM Guidelines, 1994), the parameters and design criteria suitable for those regions have found a limited application under different conditions of other fields.

Room-and-pillar mining system (Figure 1b)is based on one- or two-phase almost complete extraction approach with the first phase creating elastic pillars after driving rooms, while during the second phase these pillars are mined out on the retreat. The room-and-pillar mining method is a type of open stoping used in near horizontal deposits in reasonably competent rock, where the roof is supported primarily by pillars and, depending on the roof conditions, by rock bolts or other types of support. The ore is excavated as rectangular shaped rooms or entries in the ore body seam, leaving parts of the ore between the entries as remnant pillars to support the hanging wall or immediate roof strata.

Longwall mining (Figure 1a) is the most efficient mining system especially suitable for mining thin seams, usually for soft rock (coal, potash) but also for hard rock mining (metals) - Hustrulid, 1982. It enables mining of nearly the complete resource. In this method, the width of the panel varies from 150 to $300 \mathrm{~m}$ and length from 1,000 up to 3,500 metres. The average thickness of the deposit varies from 2 to 5 metres. In hard rock deposits, longwall mining aims to maintain near-continuous behaviour of the near-field rock mass, which requires a strong and competent hanging wall and footwall rock mass. The area located in front of the face needs to be supported by a series of hydraulic roof supports.

They temporarily hold up the roof strata and protect the working space for the continuous miner and chain conveyor. When each slice of rock is removed, the set of longwall, i.e. hydraulic roof supports, the conveyor and the longwall shearer machinery are moved forward. As a longwall equipment advances along a panel, the roof behind is allowed to fall down. 
a)

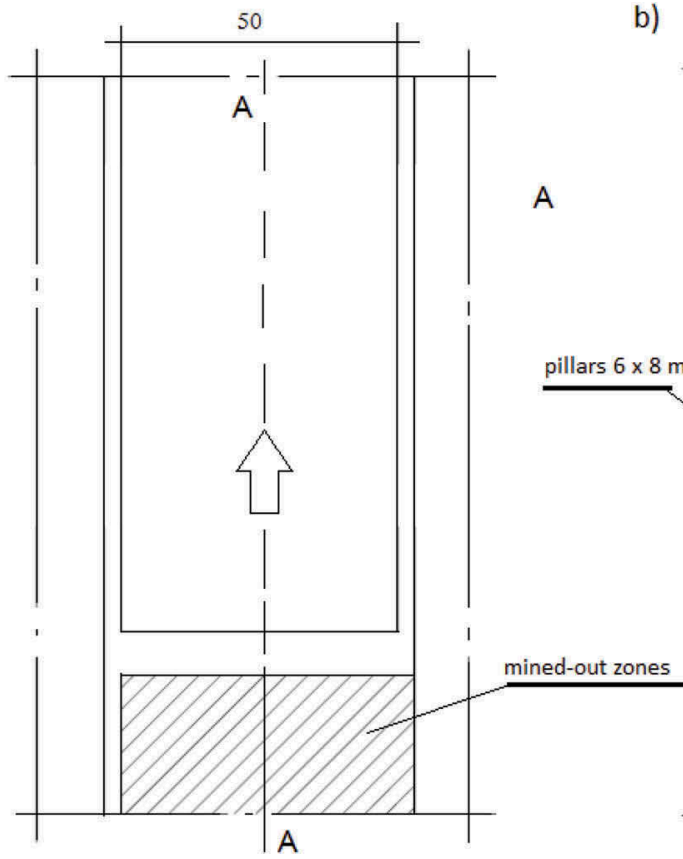

b)

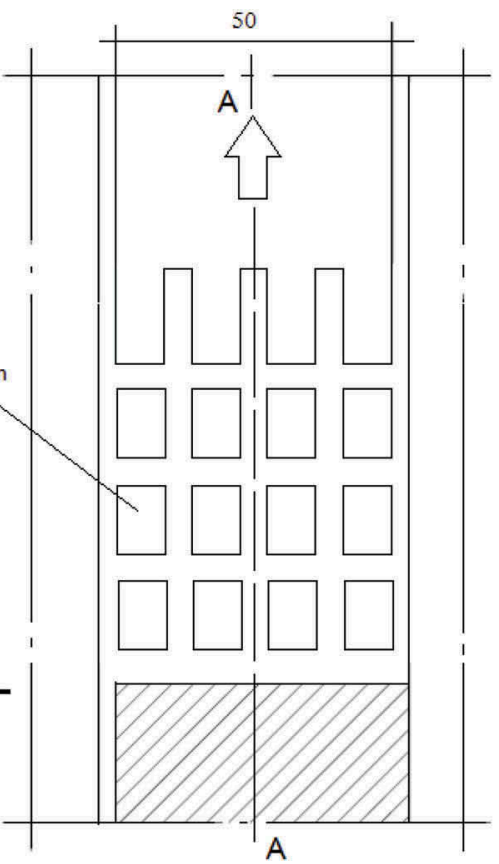

Figure 1. General schemes of (a) longwall mining system and (b) one-phase room-and-pillar mining system - both geometries of mine workings used in numerical analysis.

\section{INTRODUCTION INTO THE GEOMECHANICAL MODELING}

As a basic physical model for the problem, the multi-plate overburden model has been accepted with the following simplifying assumptions (Figure 2):

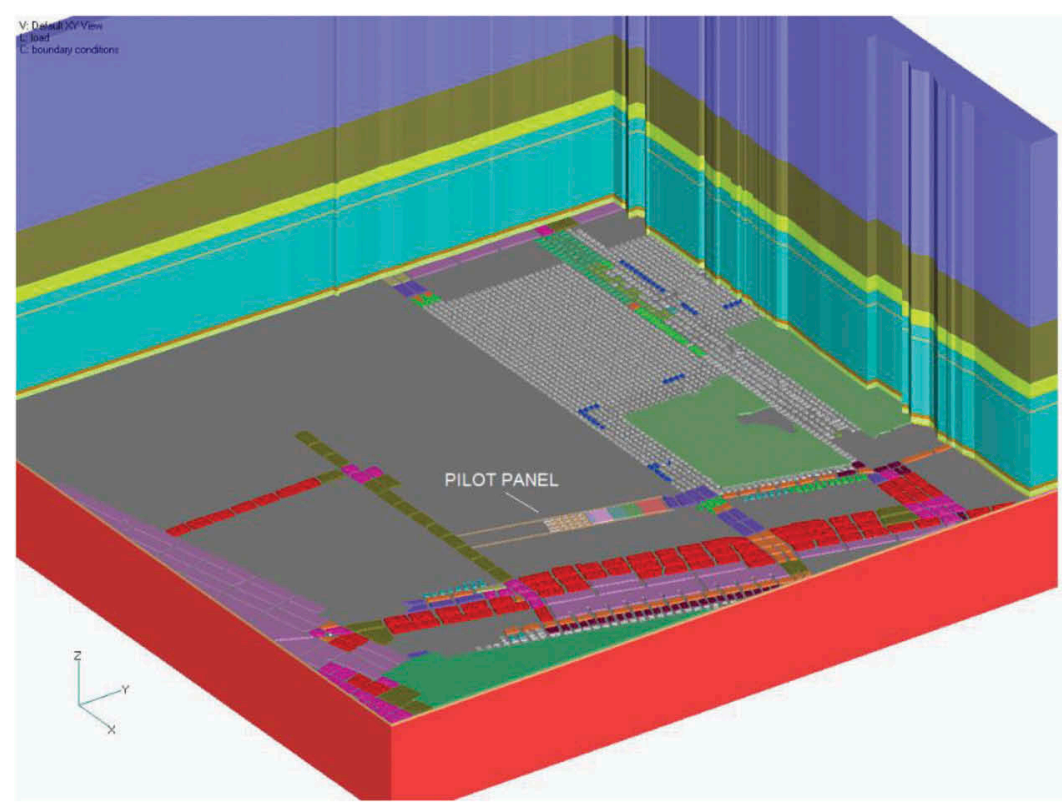

Figure 2. General view of the numerical model. 
- overburden strata consists of several homogeneous rock plates reflecting the real lithology in the area,

- technological and remnant pillars work effectively within post-critical phase (elastic-plastic with strain softening behaviour),

- the value of carried loads depends on pillar size and actual extraction ratio.

Geomechanical problem solution and results visualization were based on the NEi/NASTRAN computer program code utilizing FEM in three dimensions. It was understood that all but the pillars' materials reveal a linear-elastic characteristics, whereas copper ore rock mass behaviour is represented by elastic-plastic with strain softening kind of mechanical model. The entire numerical model general boundary conditions were described by displacement based relationships. More information on the applied solution method may be find elsewhere (Pytel, 2003).

Numerical experiments modeling the three-dimensional mine layout were performed, using two boundary condition sets defined by presence or absence of horizontal additional stress. The determined stress/deformation states were used afterwards for quantitative characterization of the effect of horizontal tectonic stress on system behavior and safety (Orlecka-Sikora and Pytel, 2013) using the indicators called safety margins related to well-known shear type failure criterion based on the Coulomb's theory (Jaeger et al., 2007):

$$
\sigma_{1}=\sigma_{c m}+A \cdot \sigma_{3}
$$

where: $\sigma_{\mathrm{cm}}$ - unconfined compression strength in rock mass scaled down acc. to the Hoek's (2007) approach, in [MPa], $\sigma_{1}, \sigma_{2}$ - major and minor principal stress respectively (compression - positive), in [MPa], A- positive material constants dependent on angle of internal friction $\varnothing$ in rock mass:

$$
A=\frac{1+\sin \emptyset}{1-\sin \emptyset}
$$

Thus, the respective safety margin has been formulated as follows:

$$
M_{c}=\sigma_{c m}+A \cdot \sigma_{3}-\sigma_{1}
$$

Rock mass instability potential is indicated by safety margin value smaller than zero. Instead of safety margins one may use so called safety factors based on the same failure criterion and formulated as:

$$
F_{c}=\frac{\sigma_{c m}+A \cdot \sigma_{3}}{\sigma_{1}}
$$

One may use another type of safety factor, based on Hoek-Brown theory (Pariseau, 2009).

The technological pillars, presented in this paper, located within this development areas are characterized by $\sigma-\varepsilon$ relationship shown in Figure 3, with the rectangular pillar bearing capacity value given by Pytel and Chugh (1992) in the following form:

$$
\sigma_{p}=0.294 \cdot \sigma_{c}\left(1-\frac{B}{5 L}\right) \cdot \sqrt{\frac{B}{H_{p}}}
$$

where: $\sigma_{c}$ - uniaxial compressive strength of rock specimen tested in the laboratory, in [MPa], $B$ and $L$ - pillar dimensions, in [m], $H_{p}$ - pillar height, in [m]. 


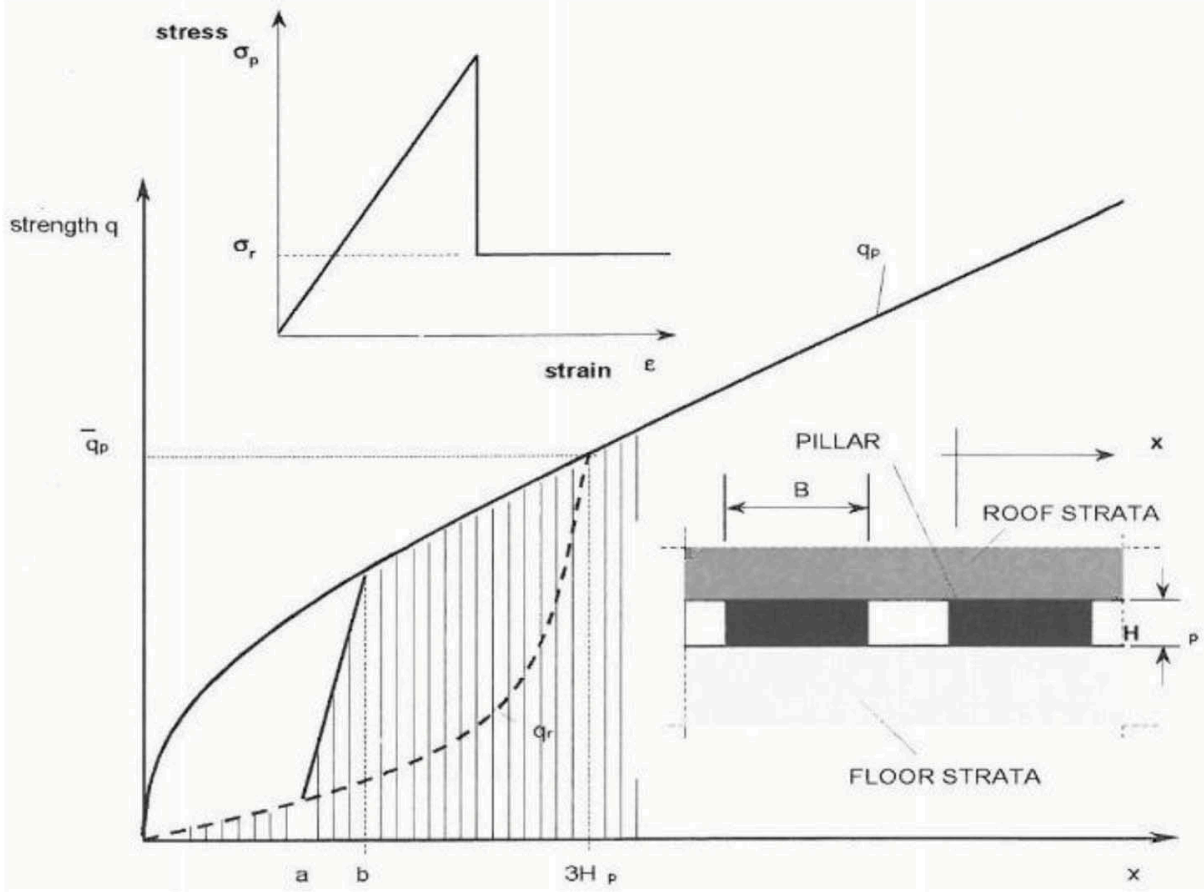

Figure 3. Stress-strain relationship for yield pillars.

The uniaxial compressive strength should be calculated for rock sample having cube size or diameter $d=5.08 \mathrm{~cm}$. It is assumed that Eq. 5 deals with all kinds of rocks, therefore it may be utilized not only in coal but also in metal mines. Furthermore it is assumed that with load increasing, pillar behaviour characteristics transform from critical into a post-critical type with bearing capacity reduction due to pillar yielding (elastic-plastic model with softening). It is also assumed that residual pillar strength $\sigma_{r}$, being a portion of the pillar bearing capacity (pillar critical strength) $\sigma_{r}$, may be determined by integrating rock strength (peak or residual) over the horizontal cross-section of the pillar (Pytel, 2003). Geomechanical problem solutions were based on the planned geometry of the hypothetical mining parcel. The considered panel mine workings' geometries with its detailed spatial finite element approximation is presented in Figure 4. Two different mining systems were analyzed. The first one (variant A) is based on longwall system, while the second one (variant B) based on room-and-pillar mining system. Height of the assumed mining drifts, located at the depth of $751 \mathrm{~m}$, in both cases was accepted to be $2 \mathrm{~m}$.

Each model has been analysed from the point of view of different methods of roof control, i.e. roof deflection, wooden chock support, Tekpak support (Amick et al., 1993; Barczak et al., 2003; Minova, 2017)) and cemented backfilling with 10\% of effectiveness (deflection factor $=0.1$ ). To analyze geomechanical conditions within the hypothetical mining panel, typical lithology in the Lower Silesia area (Kijewski and Lis, 1994) was assumed (Table 1). 

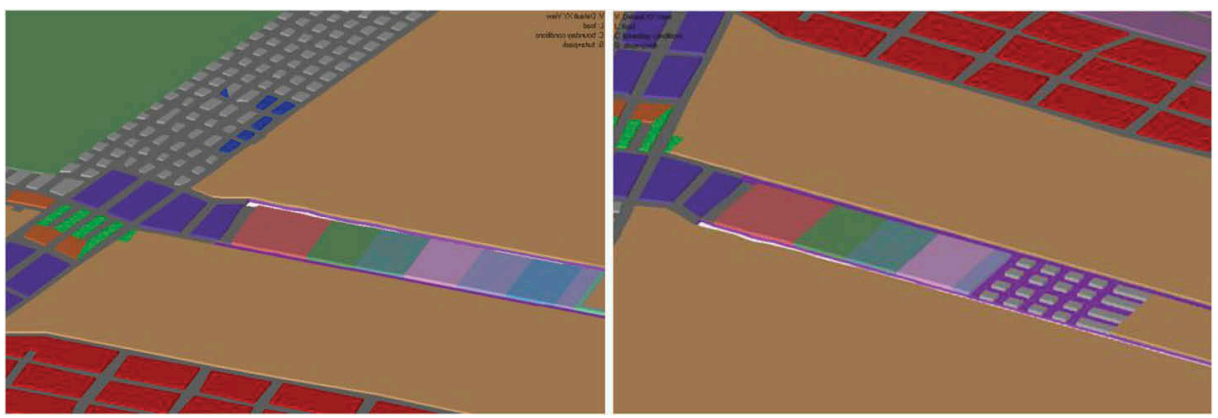

Figure 4. View of the FEM model for longwall mining system (left) and the FEM model for room-andpillar mining system (right).

\section{ANALYSIS OF SAFETY MARGIN DISTRIBUTION}

It was assumed that the so-called safety margin, representing relation between load intensity and material strength, may serve as the basic indicator of possible roof strata instability.

The safety margin have been estimated by comparing the actually computed values of components of stress-strain tensors with ultimate values characteristic for a given material determined in laboratory or in the field. This may be done using some functions of load intensity formulated in the form of various strength theories. A measure of the goodness of fit of a given strength theory to the actual conditions is simply the percentage of the instabilities which occurred in the area of interest that are explained by the theory. The Coulomb strength theory has been chosen (see above) as the representative for the geology encountered in the pilot panel's site. The mine workings basic geometry was evaluated from safety point of view with no tectonic stress. Calculated safety margin $M_{c}$ contours above the immediate roof strata are shown in Figure 5-8 (longwall mining system) and Figure 9-12 (room-and-pillar mining system).

\section{DISCUSSION OF RESULTS}

Results of numerical analyses presented above indicate that when using longwall mining systems with roof deflection (Figures $5-8$ ), the immediate roof instability due to excessive shearing (Figure 13) may occur up to 2-3 m within roof strata unsupported or supported by wooden cribs or artificial TekPaks. However, when cemented backfilling is located within the goaf area these instabilities will cease completely.
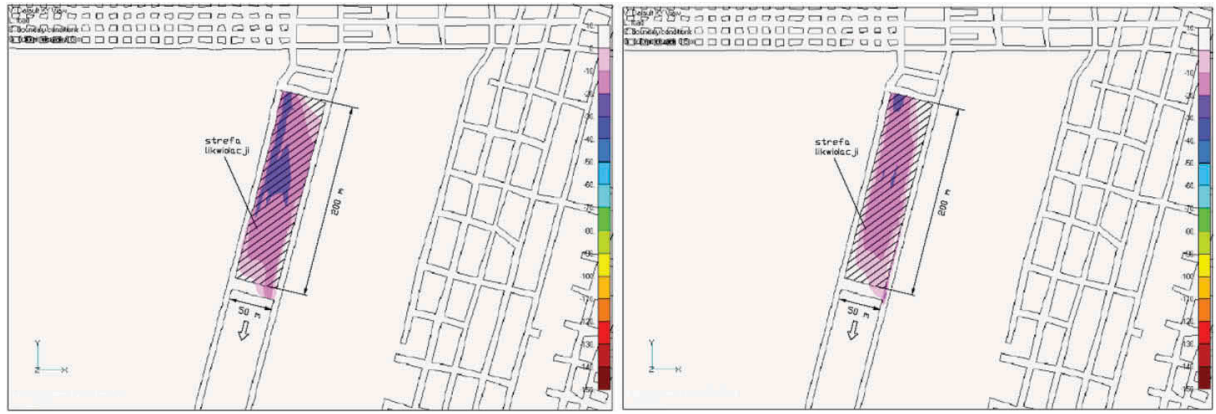

Figure 5. Safety margin distribution $0.55 \mathrm{~m}$ (left) and $1.7 \mathrm{~m}$ (right) above the immediate roof strata (longwall with roof deflection, excavation height $\mathrm{H}_{\mathrm{p}}=2.0 \mathrm{~m}$, wooden cribs support or TekPak). 


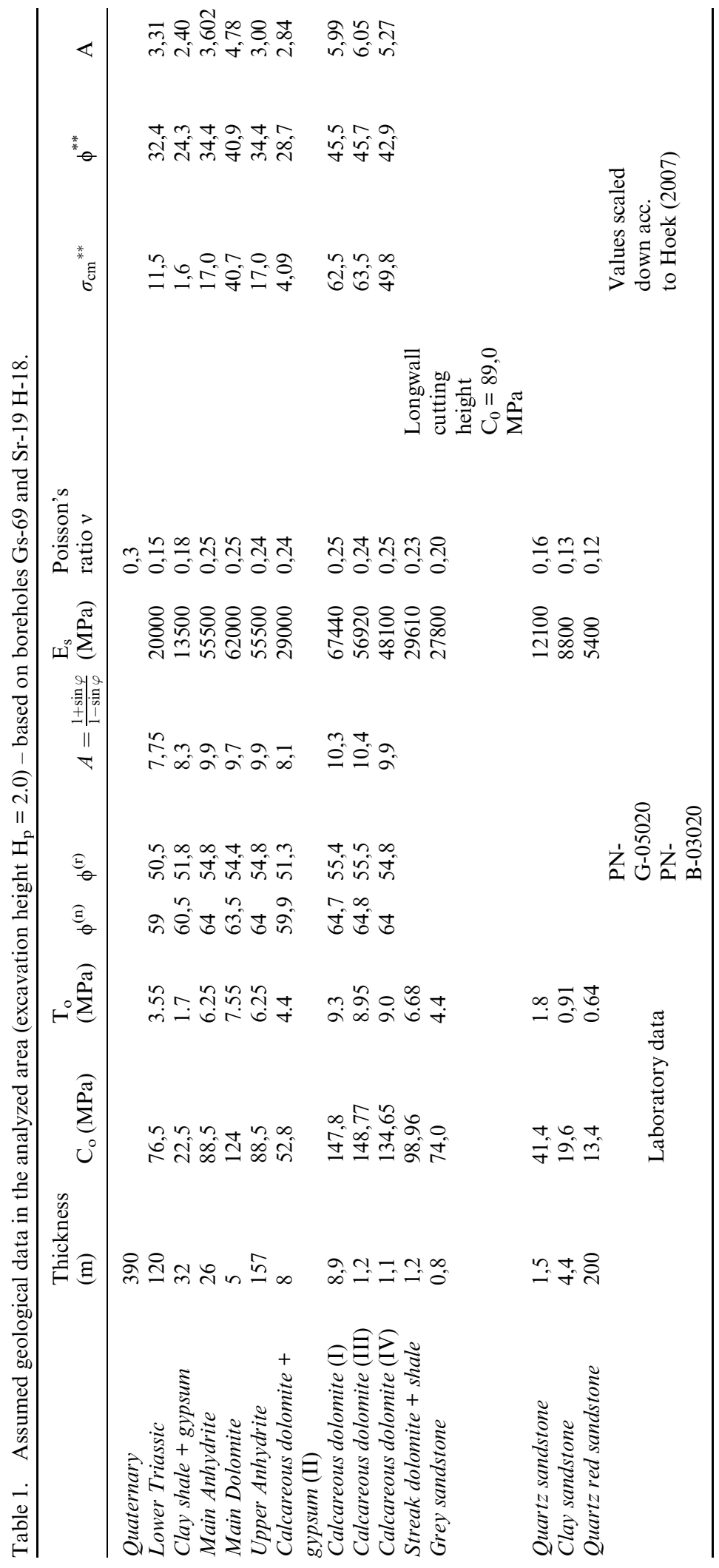



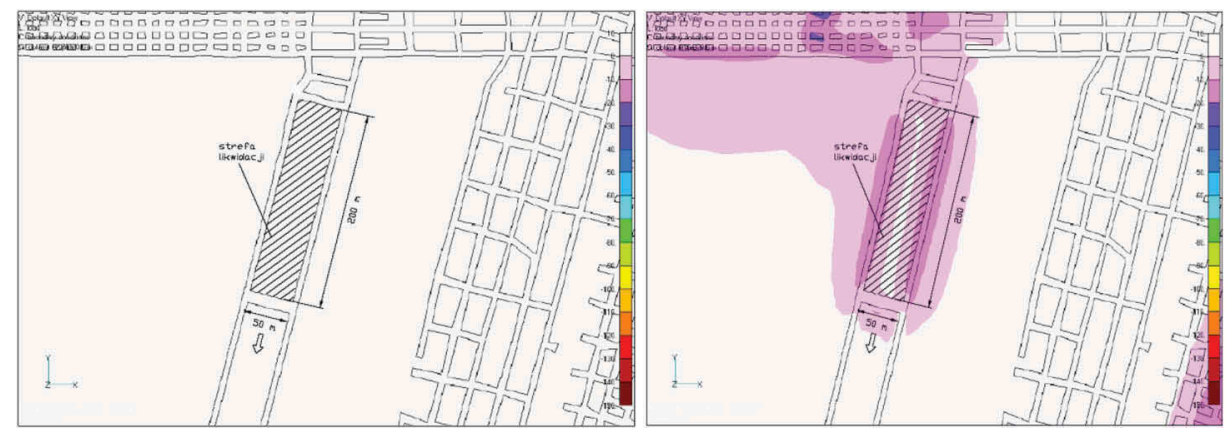

Figure 6. Safety margin distribution $7.75 \mathrm{~m}$ (left) and $15.2 \mathrm{~m}$ (right) above the immediate roof strata (longwall with roof deflection, excavation height $\mathrm{H}_{\mathrm{p}}=2.0 \mathrm{~m}$, wooden cribs support or Tekpak).
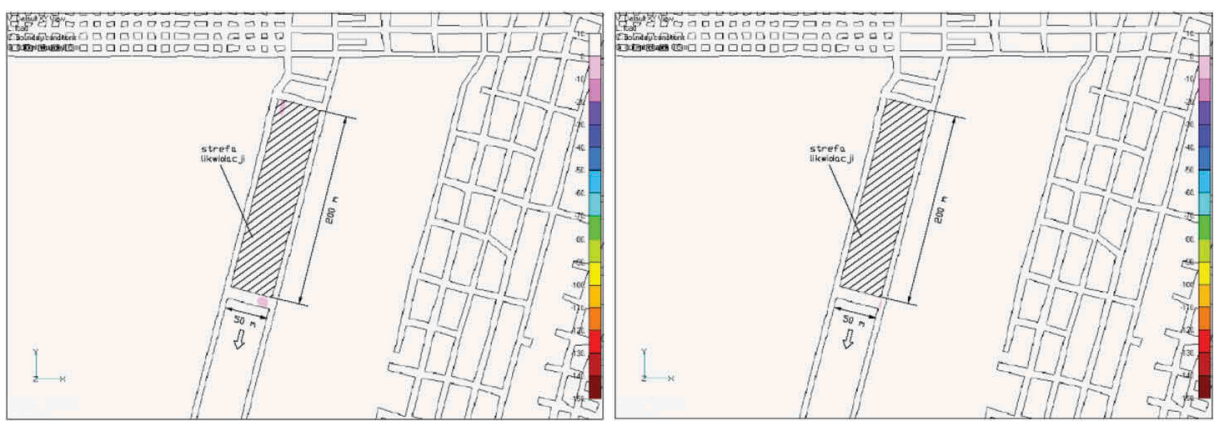

Figure 7. Safety margin distribution $0.55 \mathrm{~m}$ (left) and $1.7 \mathrm{~m}$ (right) above the immediate roof strata (longwall with cemented backfilling, excavation height $\mathrm{H}_{\mathrm{p}}=2.0 \mathrm{~m}$ ).
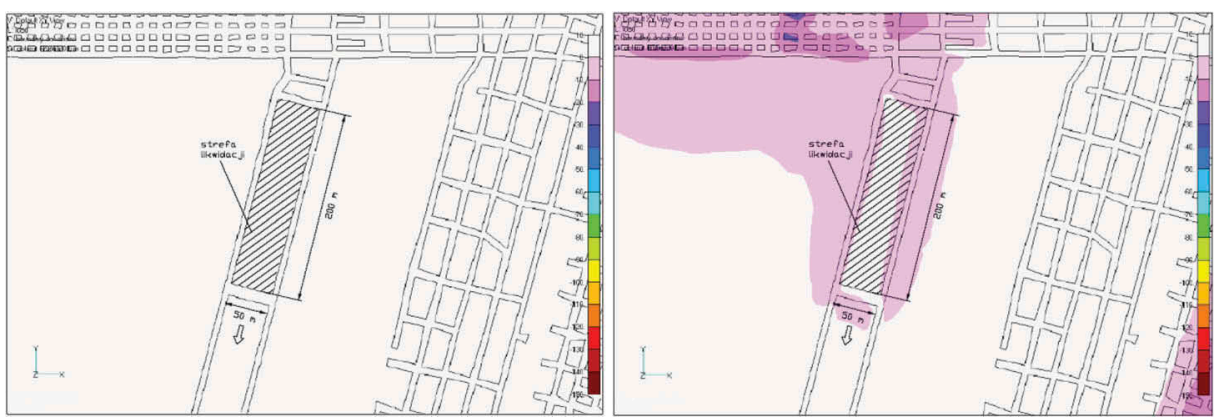

Figure 8. Safety margin distribution $7.75 \mathrm{~m}$ (left) and $15.2 \mathrm{~m}$ (right) above the immediate roof strata (longwall with cemented backfilling, excavation height $\mathrm{H}_{\mathrm{p}}=2.0 \mathrm{~m}$ ).

Analysis of the behavior of the room-and-pillar mining system showed also (see Figure 14) that independently on the rock excavation technology, main roof instability may occur about $10 \mathrm{~m}$ above the immediate roof strata due to possible excessive value of $\sigma_{1}$ principal stress resulting in rupture of the upper rock mass.

Based on the former experiences in the field of numerical analyses (Pytel, 2010; Pytel and Butra, 2010) one may conclude, that instability hazard associated with loosening of roof rock layers (due to the high tangential stresses) and their crosswise shear, which are represented by margin of safety $M_{c}$ formulated based on Coulomb's theory of failure is particularly 

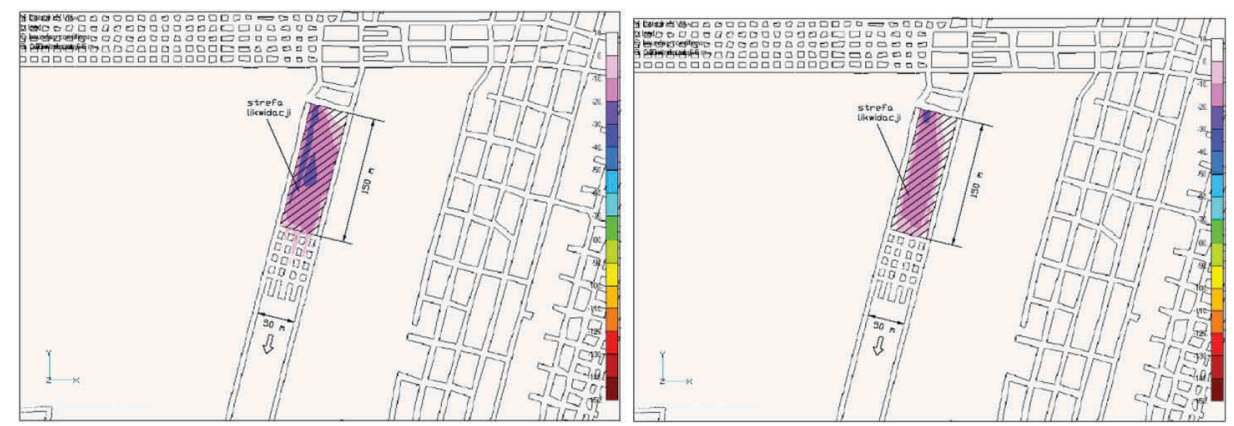

Figure 9. Safety margin distribution $0.55 \mathrm{~m}$ (left) and $1.7 \mathrm{~m}$ (right) above the immediate roof strata (room-and-pillar with roof deflection, excavation height $\mathrm{H}_{\mathrm{p}}=2.0 \mathrm{~m}$, wooden cribs support or Tekpak).
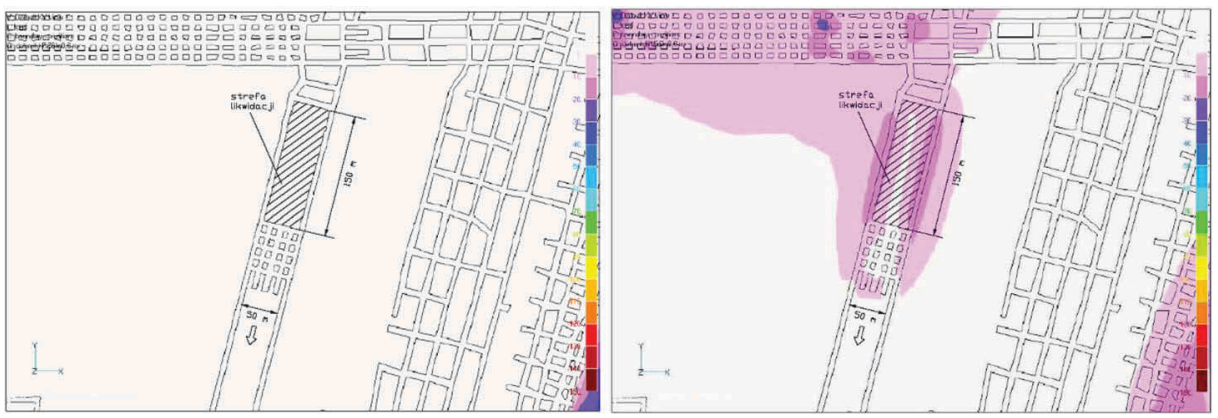

Figure 10. Safety margin distribution $7.75 \mathrm{~m}$ (left) and $15.2 \mathrm{~m}$ (right) above the immediate roof strata (room-and-pillar with roof deflection, excavation height $\mathrm{H}_{\mathrm{p}}=2.0 \mathrm{~m}$, wooden cribs support or Tekpak).
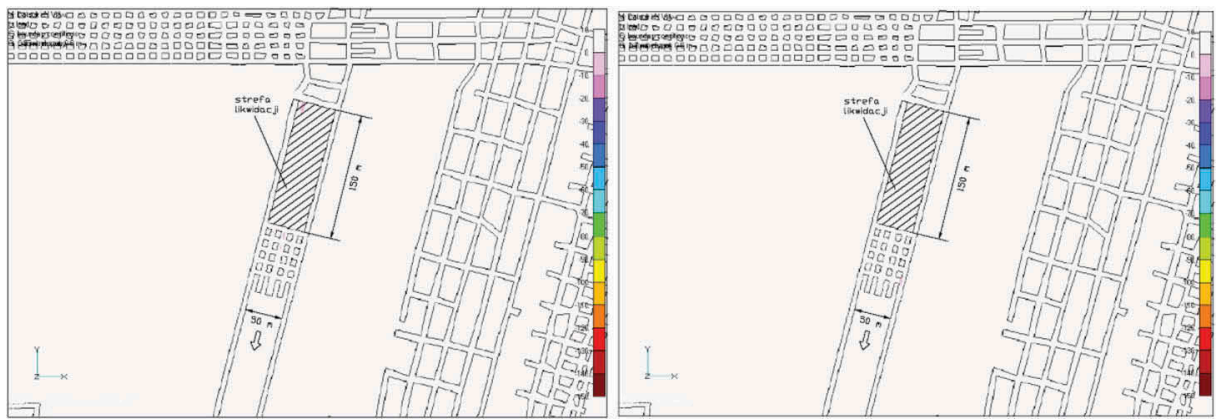

Figure 11. Safety margin distribution $0.55 \mathrm{~m}$ (left) and $1.7 \mathrm{~m}$ (right) above the immediate roof strata (room-and-pillar with cemented backfilling, excavation height $\mathrm{H}_{\mathrm{p}}=2.0 \mathrm{~m}$ ).

important on all levels of roof layer for most real cases of mining analyzed by the presented above numerical methods.

Therefore, margin of safety $M_{c}$ is one of the key indicator of presented analysis. Installation of wooden cribs or Tekpak support within the mined out areas does not provide the expected, beneficial results in terms of safety in regard of roof falls and 


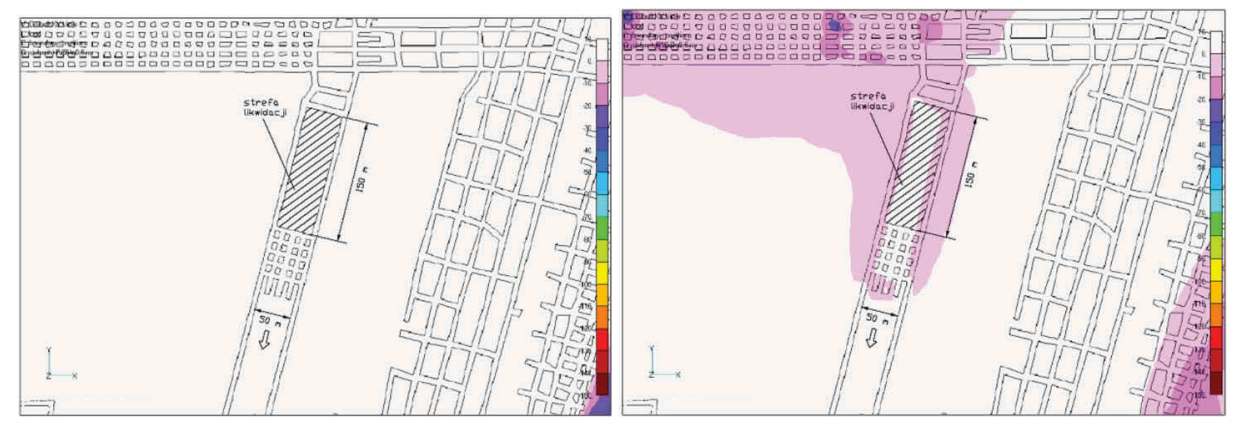

Figure 12. Safety margin distribution $7.75 \mathrm{~m}$ (left) and $15.2 \mathrm{~m}$ (right) above the immediate roof strata (room-and-pillar with cemented backfilling, excavation height $\mathrm{H}_{\mathrm{p}}=2.0 \mathrm{~m}$ ).

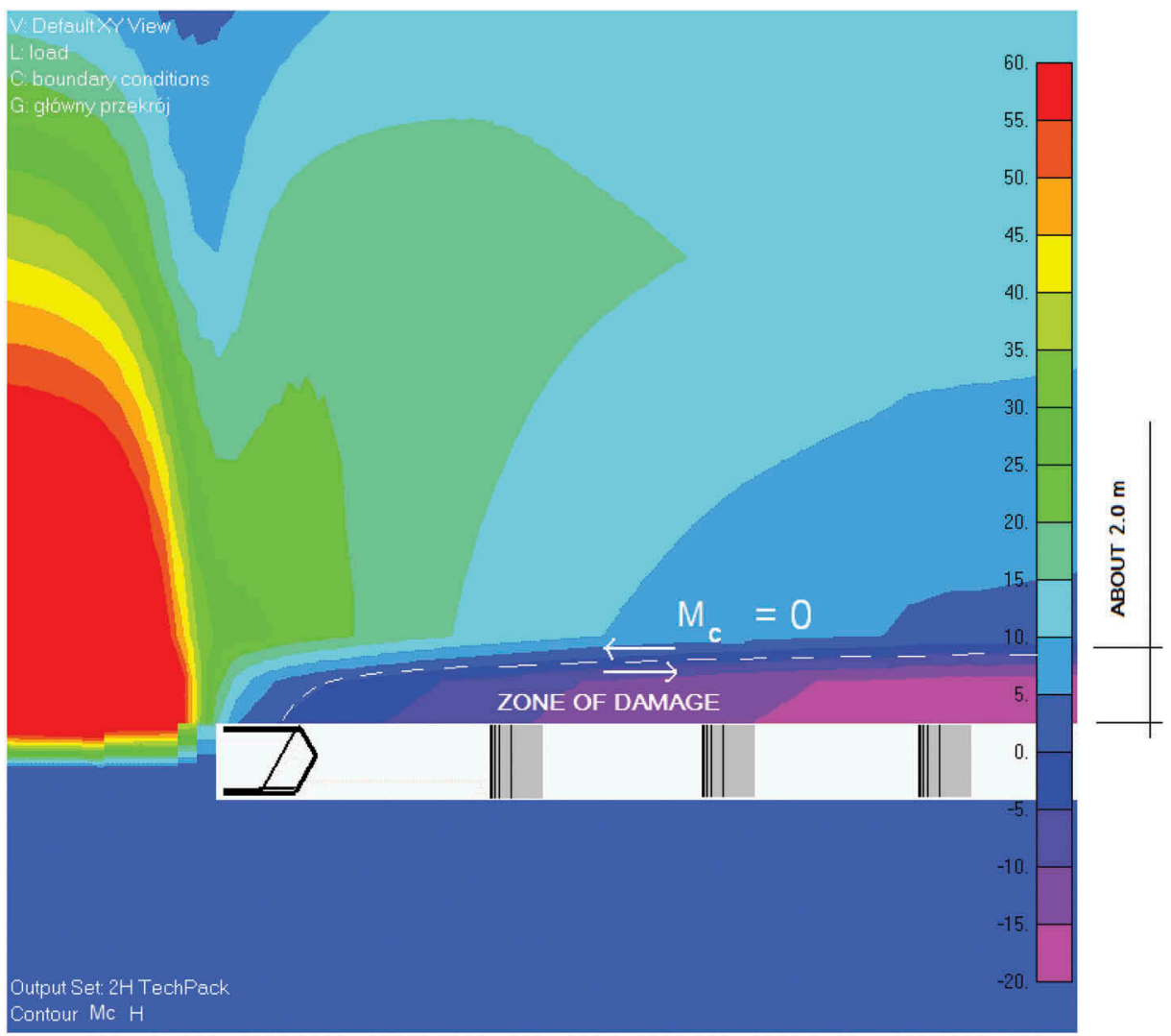

Figure 13. Zone of possible shearing type damage allowing immediate roof strata falling down.

rockburst. Their effectiveness is comparable to the effect of mechanized support, however, a significant role of the last one as an element protecting the working zone against the local roof falls cannot be excluded. Wooden cribs and Tekpak support may be treated as an element of roof falls prevention, up to $8 \div 10 \mathrm{~m}$ within the roof strata (see Figure 14). This value depends on the opening height.

The effect of density of artificial support location within the goaf area (Figure 15, Variants I-IV) on safety margin values $\mathbf{M}_{\mathrm{c}}$ is illustrated on the example of the same pilot panel which 


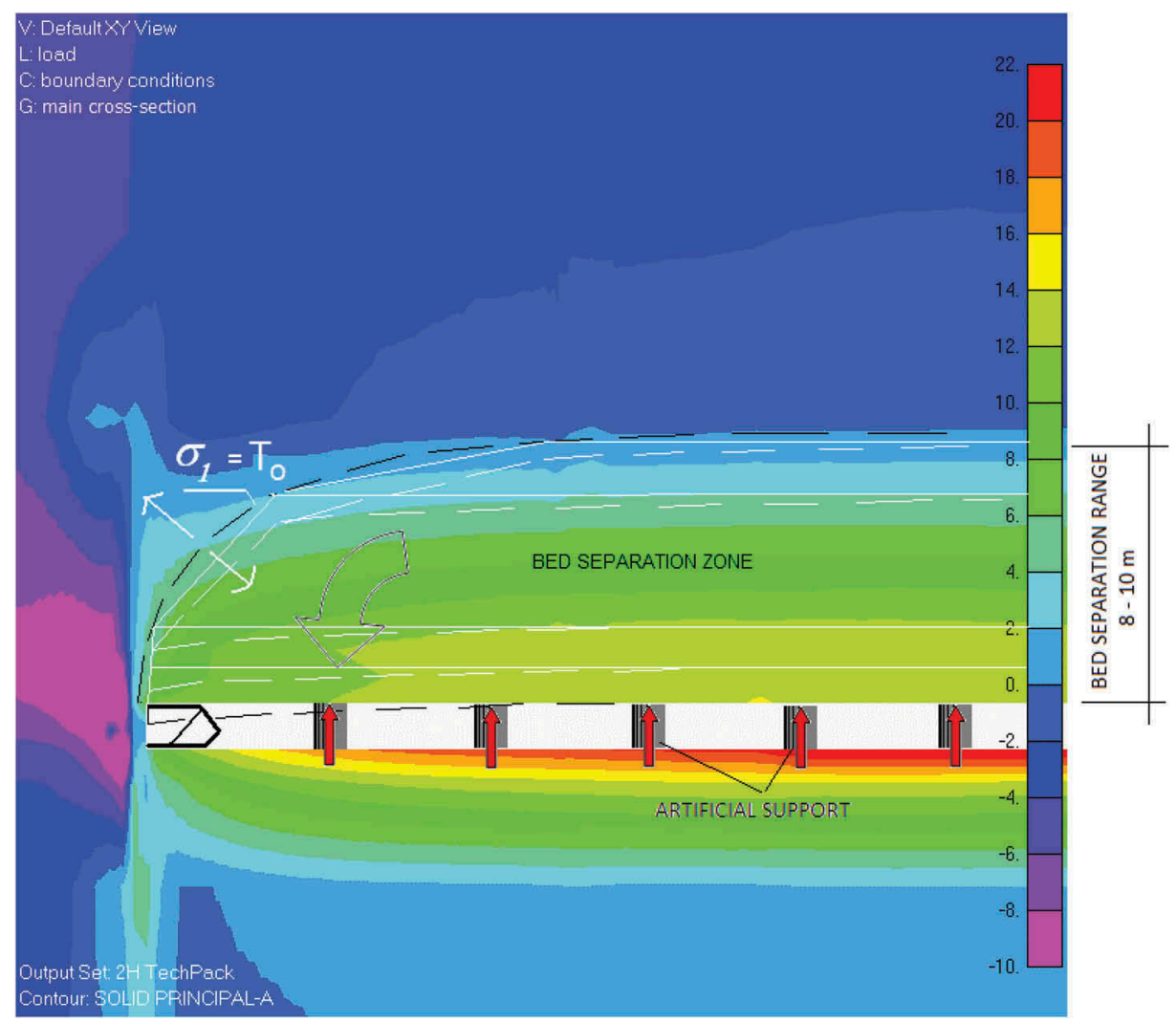

Figure 14. Possible bed separation zone due to excessive value of $\sigma_{1}$ principal stress.

was analyzed above. Selected computation results indicate that from point of view of shear type instability, the rock strata behavior is not sensitive on the density of Tekpak location within the goaf area (Figure 16). This means for the mining practice, that supports of the Tekpak type are not able to resist effectively against the horizontal bed separation within the immediate roof strata due to the eccessive shearing stress. Moreover, this kind of roof suport does not secure roof strata against the rupture at the mutual contact surfaces. Therefore the artificial Tekpak suport may successfully carry out only the weight of the separated strata unless it is less than the support load capacity.

In presented numerical analyses there were utilized extremely unnfavouring values of rock strength parameters scaled down to in-situ rock mass conditions acc. to Hoek's approach. This way, the lower bound of safety has been determined, while the upper safety bound has been assessed using the laboratory obtained strength parameters reduced by the material design coefficient $\gamma_{\mathrm{m}}=0,9$ and the rock cleavage factor $\mathrm{k}_{1}=1 / 1,05$. Selected calculation results are presented in Figure 17.

The obtained results also indicate significant safety improvement when laboratory determined rock mass strength parameters have been used. This may prove that the actual values of safety margin distribution along the line A-A (Figure 1) may be located somewhere between these two curves describing the upper and lower bounds of safety. Concluding that one may finally assume that the zone of possible roof strata separation moves definitely to goaf area.

Based on numerical analyses of considered mining parcels one may conclude, that support of the roof strata by the use of cemented backfilling guarantee an appropriate level of safety, 


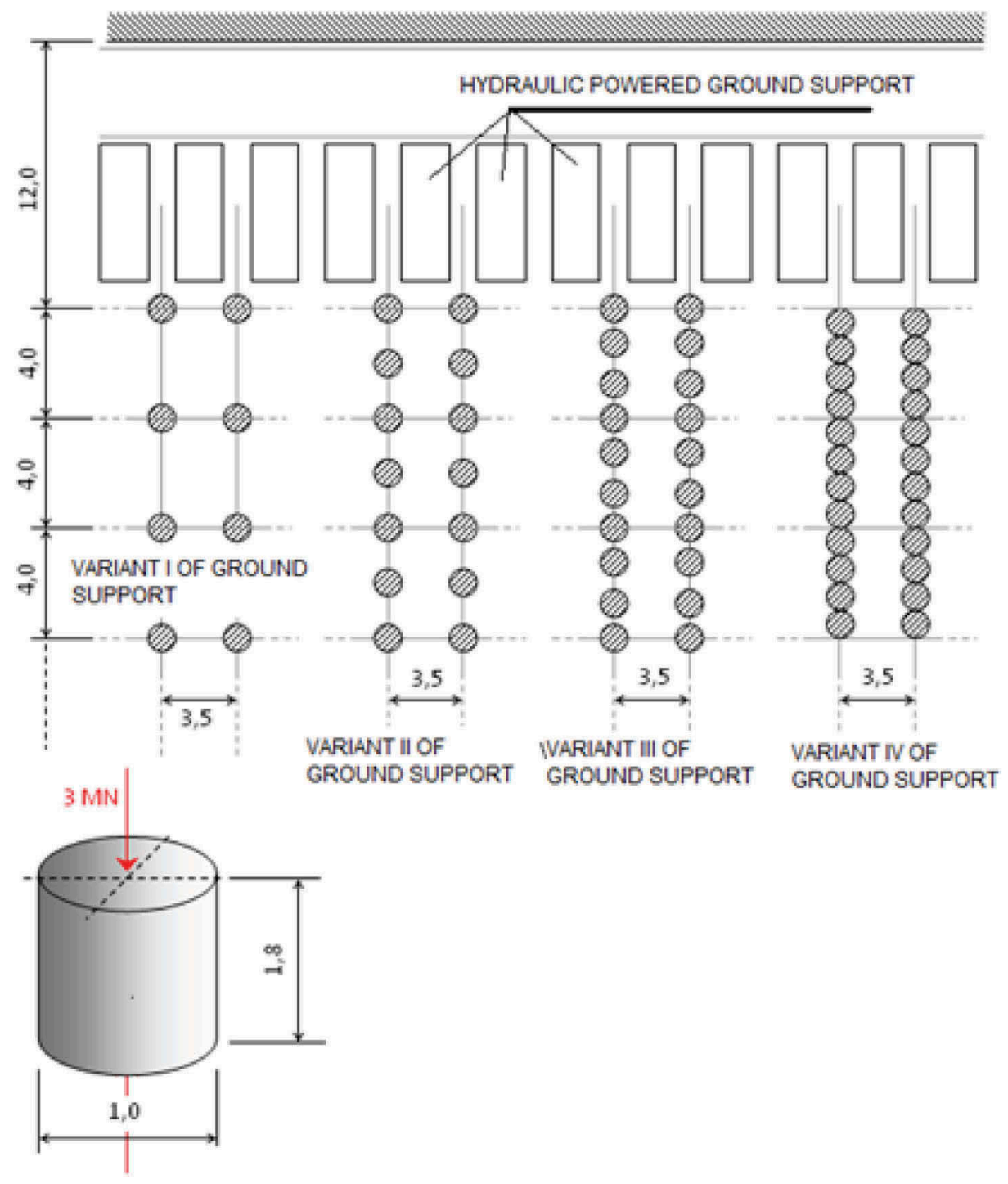

Figure 15. Variants of artificial supports' location within the pilot panel adjacent goaf area.

regardless on the size of opening and mining-geological conditions what is presented on Figures $18-19$. Yielding of the rock mass on the mining front, which is typical for a classical room-and-pillar mining system leads to substantial rockburst and roof falls hazard reduction. Applying of a lighter support may be effective only when geology of the immediate roof would not be prone to cracks formation and delamination in the roof layers located deeper that $6 \div 8 \mathrm{~m}$ in the roof outer surface.

Application of mechanical excavating system at a depth greater than $700 \mathrm{~m}$ where the dynamic pressure of the rock mass is higher, is associated with significant difficulties with roof control, especially when the technology with possible roof falls is used or lighter support like wooden cribs or Tekpaks are used. This stipulation has been proved in reality few weeks after the mechanized mining system was commenced in the pilot 


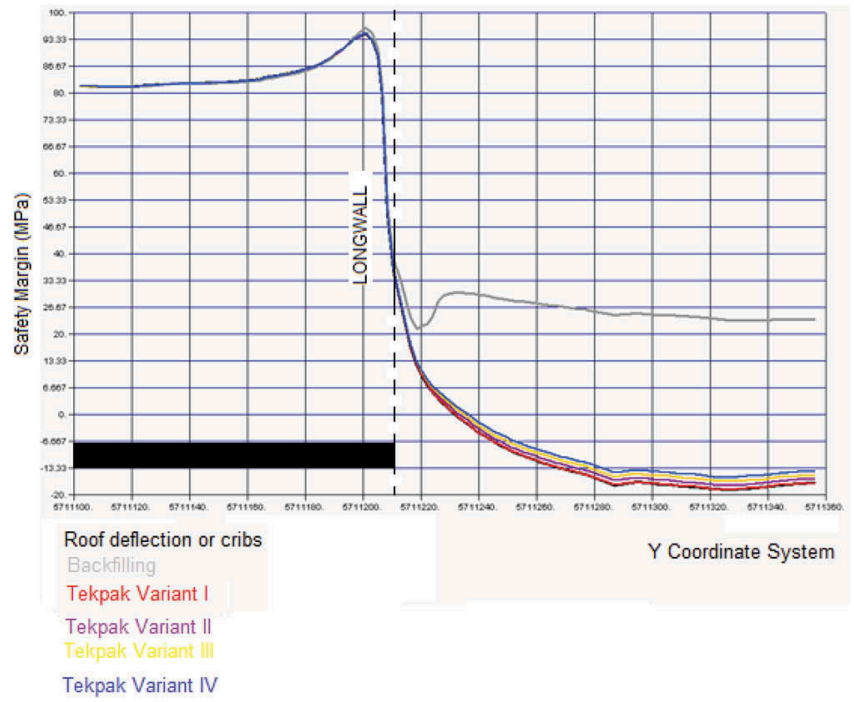

Figure 16. The effect of roof suport in goaf area on values of safety margins $\mathrm{M}_{\mathrm{c}}$ along the line A-A (Figure 1) at the level $1.7 \mathrm{~m}$ above the immediate roof strata.

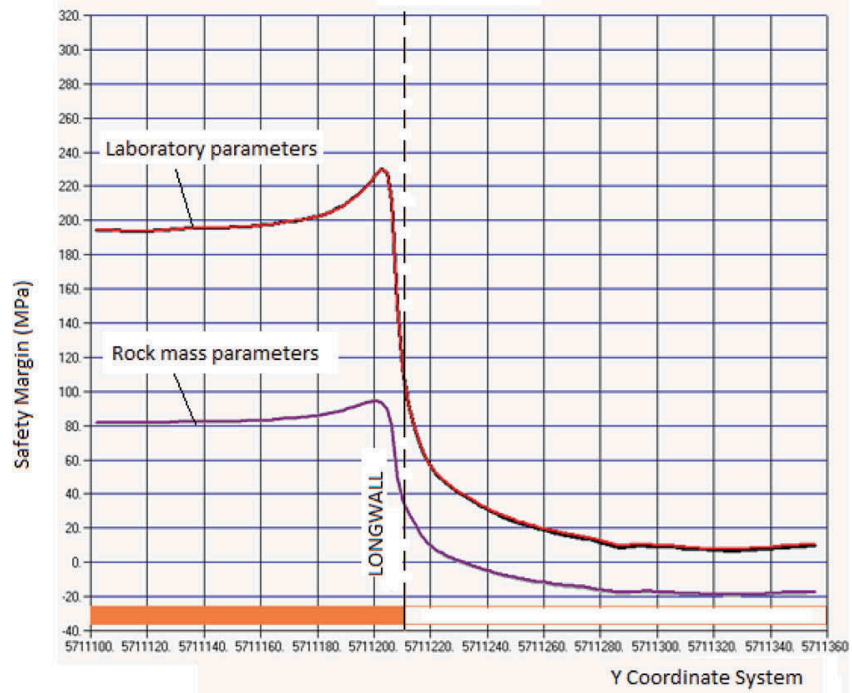

Figure 17. The effect of rock mass parameters assessment: values of safety margins $\mathbf{M}_{\mathrm{c}}$ along the line A-A (Figure 1) at the level $1.7 \mathrm{~m}$ above the immediate roof strata.

panel, when extremely large $(36 \times 50 \times 2 \mathrm{~m})$ slab of immediate roof stratum felt down, fortunately without any casualties or severe loses (see Figure 20). Wooden cribs placed in goaf area have disappeared completely, crushed there between immediate roof and floor strata. 


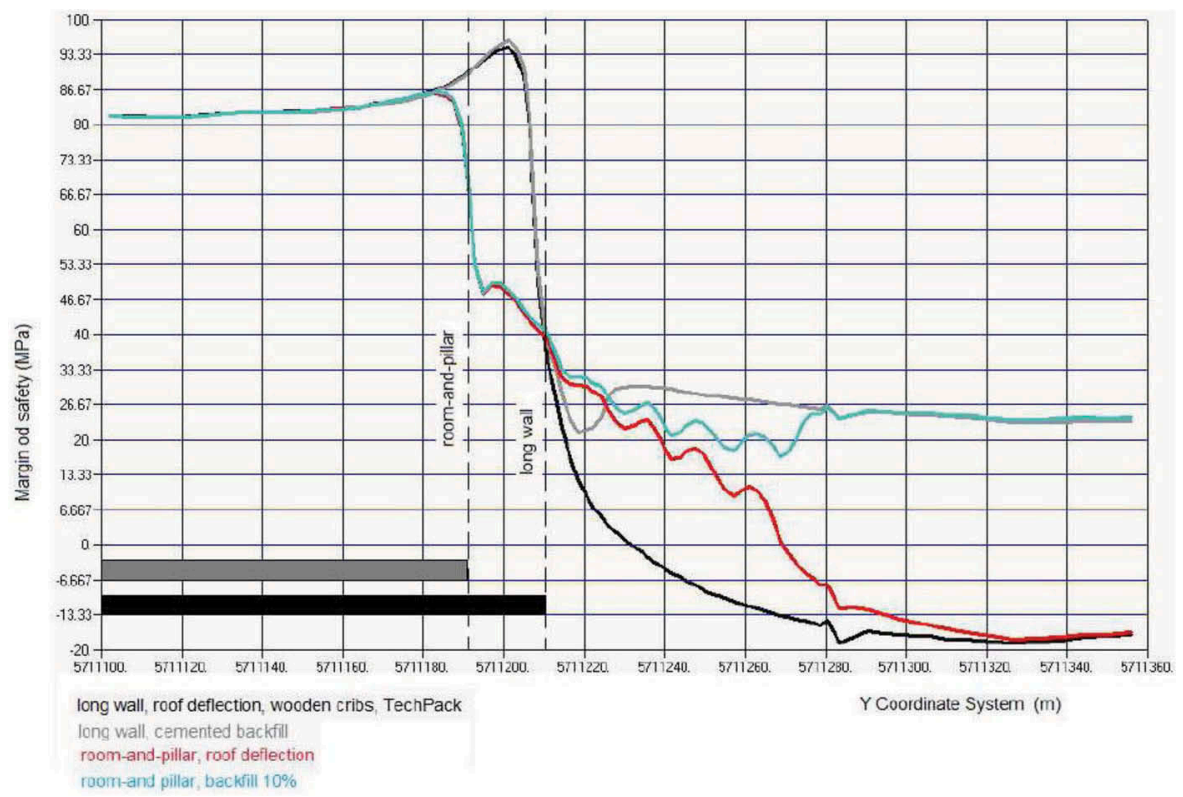

Figure 18. Values of safety margin $\mathrm{M}_{\mathrm{c}}$ along the line A-A in the pilot panel (see Figure 1) in dolomite III, $1.7 \mathrm{~m}$ above the immediate roof strata.

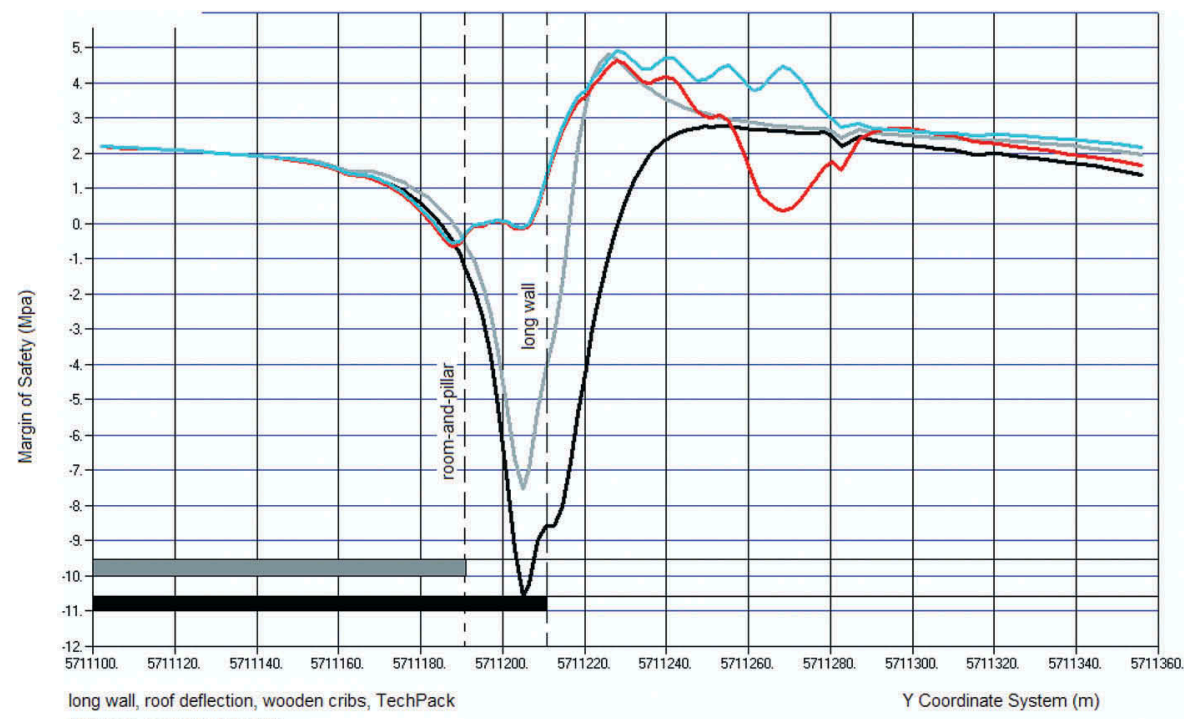

long wall cemented backfil

room-and-pillar, roof deflection

room-and pillar, backfill 10\%

Figure 19. Values of safety margin $\mathrm{M}_{\mathrm{c}}$ along the line A-A in the pilot panel (see Figure 1) in dolomite II, $15.6 \mathrm{~m}$ above the immediate roof strata. 


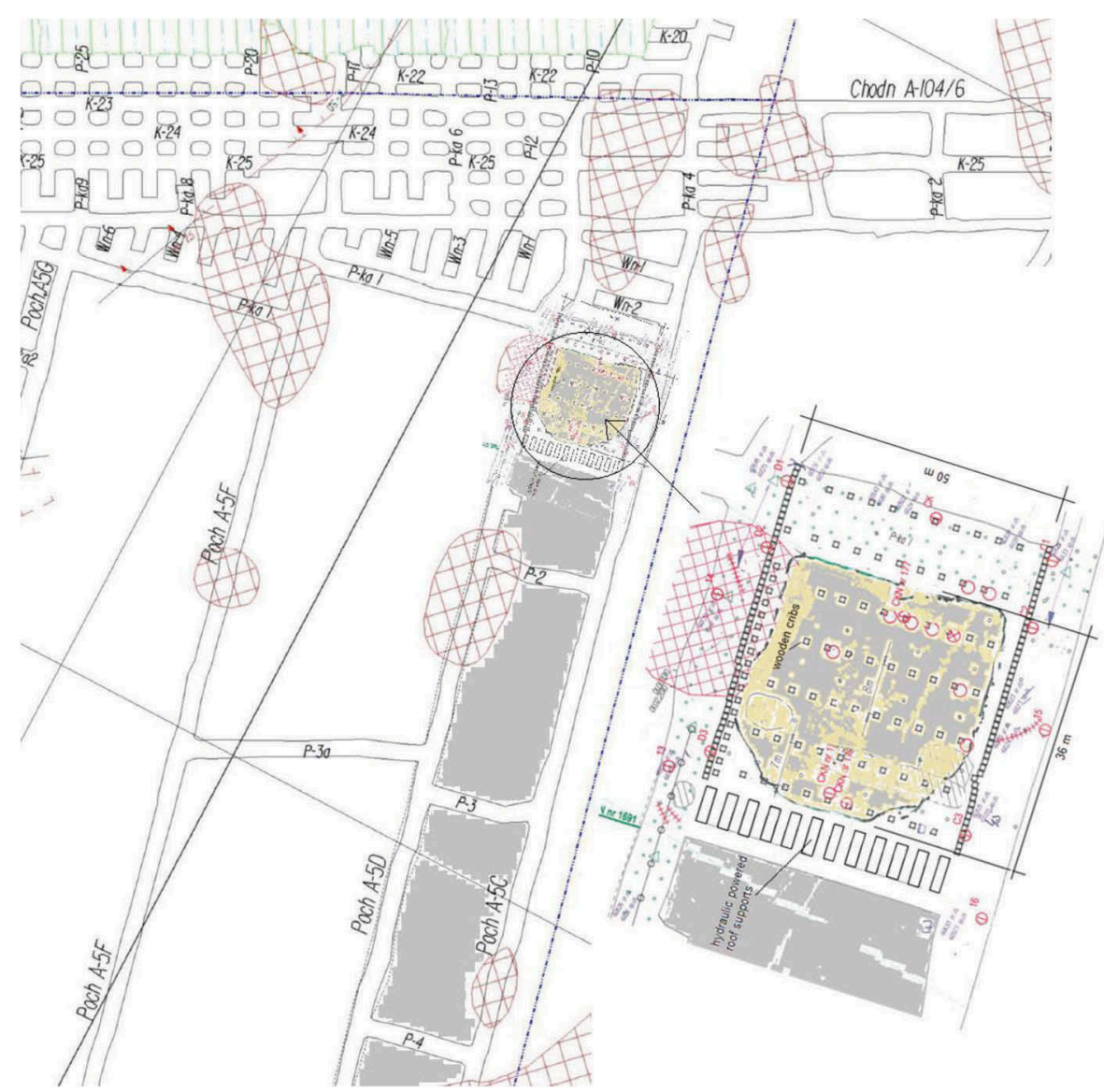

Figure 20. Massive roof fall observed in the pilot panel at the beginning of the ore extraction.

\section{CONCLUDING REMARKS}

The above presented results of numerical modeling of rock mass behaviour when exploited in the pilot panel using (a) the mechanized longwall system and/or (b) room-and-pillar mining, are the base of the following conclusions to be drawn:

A. It is confirmed that increasing the excavation height from 1.2 to $2.0 \mathrm{~m}$ induced unfavorable effect on geomechanical safety, however the scale of this phenomenon is not so large as one could expect.

B. It was stated, that increasing the depth of exploitation has unfavorable impact on safety in the vicinity of mining front. The presented results of performed calculations have proved, that the value of $M_{c}$ parameter is very high on larger depth. It means that the transition from the safe to danger zone occurs very rapidly, even at $10 \mathrm{~m}$ distance. On smaller depth this distance reach the distance of about 20-30 m.

C. The experience to date in the field of numerical analysis shows that the risk of instability phenomena associated with the possibility of loosening the rock layers (due to excessive tangential stress) and their lateral shearing, represented by the value of the $M_{c}$ safety reserve formulated on the basis of Coulomb's strength hypothesis, is relevant for all levels of the roof strata, for most real cases of exploitation analyzed by numerical methods. Therefore, the safety margin $M_{c}$ is the leading indicator of the risk analysis performed in this study. 
D. It is assumed that the negative values of Mc safety margins determined for the level of $1.15 \mathrm{~m}$ above the roof indicate a local rock fall threat. However, in the case of locations above $8.0 \mathrm{~m}$ above the ceiling, for which the value of the safety margin is less than zero, one can conclude about a significant rock burst hazard.

E. Rockburst hazard estimated on the basis of calculated spatial distribution of safety margins, which are a practical indicator of the degree of rock mass effort and the distance of appropriately formulated quantifiers of the current state of stress from the boundary surface of destruction, is in essence a relative assessment, allowing to identify the best solution from a number of proposed solutions from a risk point of view.

F. The analysis of the calculation results also shows that the proposed calculation procedure and the destruction criteria used to assess the hazard fulfill their role properly, without leading to conclusions contrary to the experience and results of previous observations of the rock mass behavior.

G. For the assumed mining-geological conditions, calculated safety margin distributions indicates a real rockburst hazard when the mechanized longwall technology is applied, without the highly effective backfilling. This situation may be significantly changed by including into the analysis the presence of high horizontal stresses, which haven't been considered due to the lack of the reliable data.

H. Because the presented results of numerical calculations were obtained by applying a drastic reduction of rock strength parameters according to the Hoek' approach, all the conclusions and reservations formulated above have extremely conservative character in the sense of the assumed safety margin.

\section{REFERENCES}

Amick, M., Mazzoca, J., and Vosefski, D. 1993. The use of foamed cement cribs at American Electric Power Fuel Supply Meigs Division, in Proceedings of 12th International Conference on Ground Control in Mining, S.S. Peng, ed., West Virginia University, pp. 55-58.

Barczak, T.M., Chen, J., and Bower, J. 2003. Pumpable roof supports: developing design criteria by measurement of the ground reaction curve, in Proceedings of 22nd International Conference on Ground Control in Mining, S.S. Peng, ed., West Virginia University, pp. 283-293.

Butra J., Debkowski R. and Pytel, W. 2001. Bump Hazard Control in Deep Copper Mines in Poland. Proc. of the 10th Int. Symp. On Mineral Planning and Equipment Selection, New Delhi, 2001, pp. 761-768.

Hoek, E. 2007. Practical Rock Engineering. Retrieved from https://www.rocscience.com.

Hustrulid, W.A. 1982. Underground Mining Methods Handbook. New York: SME-AIME.

Hustrulid, W.A. and Bullock R.L. 2001. Underground Mining Methods: Engineering Fundamentals and International Case Studies. Society of Mining Engineers. ISBN 978-0-87335-193-5, 728 pp.

Jaeger, J.E., Cook N.G.W. and Zimmerman, R. 2007. Fundamentals of Rock Mechanics. Wiley and Sons, $488 \mathrm{pp}$.

KGHM Guideline concerning the roof deflection method of mining in underground copper mines (in Polish), Lubin, 1994.

Kijewski P. and Lis, J. 1994. Geomechaniczne wlaściwości skal z obszaru LGOM - próba systematyki. Sci. Rep. of Institute of Geotechnics and Hydrotechnics, Wroclaw University of Science and Technology, pp. $103-110$.

Mark, C. 1990. Pillar design methods for longwall mining. Pittsburgh, PA: U.S. Department of the Interior, Bureau of Mines, IC 9247.

Minova. 2017. TekpakTM Pumpable Crib. The Advanced Pumpable crib System. www.minovaglobal.com NEi/Nastran (Version 9.2) [Computer software]. Westminster, CA: Noran Engineering, Inc.

Orlecka-Sikora, B. and Pytel, W. 2013. Integration on geomechanical and geophysical analysis methods for the prediction of seismic events in underground mining. In: Rock Mechanics for Resources, Energy and Environment - Kwasniewski \& Lydżba (eds), Taylor \& Francis Group, London.

Pariseau, W. G. 2009. Design Analysis in Rock Mechanics. Taylor and Francis, 499 pp.

Pytel W.M. and Chugh, Y.P. 1992. Design of Partial Extraction Coal Mine Layouts for Weak Floor Strata Conditions. Proc. of the Workshop on Coal Pillar Mechanics and Design, Information Circular 9315, U.S. Bureau of Mines 1992, pp. 32-49. 
Pytel, W. 2003. Rock Mass - Mine workings interaction model for polish copper mine conditions. International Journal of Rock Mechanics \& Mining Sciences, 40, pp. 497-526.

Pytel, W. 2010. Room-and-pillar mine workings design in high level horizontal stress conditions. Case of study from the Polish underground copper mines, Rock stress and Earthquakes (ed. Xie), (C) 2010 Taylor \& Francis Group, London, ISBN 978-0-415-60165-8.

Pytel, W. and Butra, J. 2010. Mine workings design in regional pillar mining conditions - a case study from a Polish copper mine. Deep Mining 2010 - (eds. M. van Sint Jan and Y. Potvin), (C) 2010 Australian Centre for Geomechanics, Perth, ISBN 978-0-9806154-5-6

Pytel, W. and Palac-Walko, B. 2015. Geomechanical safety assessment for transversely isotropic rock mass subjected to deep mining operations. Canadian Geotechnical Journal. Oct. 2015, vol. 52 Issue 10, pp. $1477-1489$.

Mark, C. 1990. Pillar design methods for longwall mining. Pittsburgh, PA: U.S. Department of the Interior, Bureau of Mines, IC 9247.

Spisak J. and Zelko, M. 2015. Environmental aspects of raw materials SMART processing. In: Environmental Engineering and Computer Application - Chan (Ed.), Taylor \& Francis Group, London.

Spisak J. and Zelko, M. 2010. The Advanced Technologies Development Trends for the Raw Material Extraction and Treatment Area. Products and Services: from R\&D to Final Solutions, SCIYO, Croatia. 